\title{
The Cam-type Deformity of the Proximal Femur Arises in Childhood in Response to Vigorous Sporting Activity
}

\author{
K. A. Siebenrock MD, F. Ferner MD, \\ P. C. Noble MD, PhD, R. F. Santore MD, PhD, \\ S. Werlen MD, T. C. Mamisch MD
}

Received: 30 November 2010/ Accepted: 26 May 2011/Published online: 15 July 2011

(C) The Association of Bone and Joint Surgeons (B) 2011

\begin{abstract}
Background The prevalence of a cam-type deformity in athletes and its association with vigorous sports activities during and after the growth period is unknown.

Questions/purposes We therefore compared the prevalence and occurrence of a cam-type deformity by MRI in athletes during childhood and adolescence with an agematched control group.

Patients and Methods We retrospectively reviewed 72 hips in 37 male basketball players with a mean age of 17.6 years (range, 9-25 years) and 76 asymptomatic hips of 38 age-matched volunteers who had not participated in sporting activities at a high level.
\end{abstract}

Each author certifies that his or her institution approved the human protocol for this investigation, that all investigations were conducted in conformity with ethical principles of research, and that informed consent for participation in the study was obtained.

Each author certifies that he or she has no commercial associations (eg, consultancies, stock ownership, equity interest, patent/licensing arrangements, etc) that might pose a conflict of interest in connection with the submitted article.

This study was performed at the University of Bern, Switzerland.

K. A. Siebenrock ( $₫)$, F. Ferner, T. C. Mamisch

Department of Orthopedic Surgery, University of Bern,

Inselspital, CH 3010 Bern, Switzerland

e-mail: klaus.siebenrock@insel.ch

P. C. Noble

Joseph Barnhart Department of Orthopedic Surgery, Baylor College of Medicine, Houston, TX, USA

R. F. Santore

Department of Orthopedic Surgery, University of California,

Sharp Memorial Hospital, San Diego, CA, USA

S. Werlen

Department of Radiology, Sonnenhof Clinic, Bern, Switzerland
Results Eleven (15\%) of the 72 hips in the athletes were painful and had positive anterior impingement tests on physical examination. Internal rotation of the hip averaged $30.1^{\circ}$ (range, $15^{\circ}-45^{\circ}$ ) in the control group compared with only $18.9^{\circ}$ (range, $0^{\circ}-45^{\circ}$ ) in the athletes. The maximum value of the alpha angle throughout the anterosuperior head segment was larger in the athletes (average, $60.5^{\circ} \pm 9^{\circ}$ ), compared with the control group $\left(47.4^{\circ} \pm 4^{\circ}\right)$. These differences became more pronounced after closure of the capital growth plate. Overall, the athletes had a 10-fold increased likelihood of having an alpha angle greater than $55^{\circ}$ at least at one measurement position.

Conclusions Our observations suggest a high intensity of sports activity during adolescence is associated with a substantial increase in the risk of cam-type impingement. These patients also may be at increased risk of subsequent development of secondary coxarthrosis.

Level of Evidence Level II, diagnostic study. See the Guidelines for Authors for a complete description of levels of evidence.

\section{Introduction}

Increasing evidence points to the role of deformities of the proximal femur in the etiology of osteoarthritis of the hip, although the details of the pathomechanics of degenerative hip disease continue to be investigated $[1,14,16,18,27$, $30,38]$. One of the most common deformities is the camtype deformity of the femur, typically represented by a nonspherical extension of the articular surface at the anterosuperior head-neck junction [19, 37], which can lead to femoroacetabular impingement lesions and decreased range of internal rotation [12, 13, 22, 39]. 
However, the etiology of this condition remains to be determined. Some authors suggested the cam-type deformity was attributable to growth disorders and/or childhood diseases like a "silent" capital slip or Perthes disease [14, 16, 27, 38]; Murray attributed this deformity to a pattern of abnormal ossification of the proximal femur owing to either congenital factors, a low-grade infection or autoimmune reactions [27]. Evidence of a genetic basis of the cam-deformity is suggested by an increased risk of 2.8 for siblings having the same deformity as the patients [33].

Murray and Duncan [28] reported an increased prevalence of hip pain in athletes, including elite athletes, with cam-type pathomorphologic features of the femur, which, in earlier years, was better known as a pistol grip deformity [16]. Male athletes, especially those engaged in soccer, handball, and competitive track and field activities (running and jumping sports), reportedly have an earlier onset and increased risk of osteoarthritis of the hip [9, 21, 24, 25, $28,42,43]$. The prevalence of hip osteoarthritis is 3 to 8.5 times higher than in nonathletes, depending on the intensity of athletic activities and the physical loading of the hip [24, 25, 42].

There are reports regarding cam-type pathomorphologic features in young athletes, which are assumed to be attributed to the demands of the vigorous sports activities [2, 4, 20, 32]. An alternative explanation would be that during growth vigorous activities, might trigger an aberrant cam-type deformity of the proximal femur. This thought originally was formulated by Murray and Duncan in 1971 [28]. Their assumption was based on the observation that the highest prevalence $(24 \%)$ of femoral head tilt deformities occurred in adolescents who were exposed to a more active sports regime during school and who had started participating in sports activities before 14 years of age. Exposure to high sports stresses in young athletes has shown an association with functional alterations in the hip and shoulder $[3,40]$ and with morphologic features of the skeleton $[5,6]$.

We therefore asked whether: (1) the prevalence of a cam-type deformity of the proximal femur is greater in male athletes compared with nonathletes; (2) the cam-type deformity is less pronounced in childhood but increases with participation in vigorous physical activities during hip development and physeal closure; and (3) hip pain and decreased internal rotation of the hip are more frequent in male athletes than in healthy control subjects.

\section{Patients and Methods}

In a case-control study, we compared a group of basketball athletes with a group of nonathletes of the same age range. Key elements were detection of hip pain, comparison of internal rotation of the hip, and analysis of the alpha angles at the head-neck junction on MRI scans. Both groups consisted of volunteers who were recruited during a 1-year period from a professional basketball club and age-matched individuals from middle, high, and medical schools. We included males from 9 years to 25 years of age. We excluded individuals with previously diagnosed hip disease, including hip dysplasia, Perthes disease, slipped capital epiphysis, previous severe hip trauma, or previous surgery on the hip. The study was approved by the Ethical Committee and written consent was given by each participant. For all individuals of the control group and athletes younger than 18 years, written consent also was obtained from one of the parents.

The key parameter was the alpha angle and its difference between athletes and the control group. Based on the results from Pfirrmann et al. [31], a difference of $15^{\circ}$ can be expected between alpha angles in patients with a cam-type impingement and hips with proximal femora, which have been considered normally shaped. Based on the results from a large cohort study by Reichenbach et al. [35], the standard deviation of the alpha angle was $10^{\circ}$. Thus, a sample size of 29 persons per population will yield a power of $97 \%$ at a two-sided p of 0.05 .

The athletes were recruited from a cohort of 55 male members of an elite basketball club playing in the first national league of Germany. All 55 players in the team's training squad were sent written invitations to participate in this study without reimbursement; 37 of the 55 players (67\%) accepted the invitation. Athletic activity was defined as uninterrupted participation in the club's program of basketball training sessions and games since the age of 8 years. Under this program, typical training activities consisted of three training sessions and/or one game a week for 9- to 12-year-old players; four to five games or training sessions per week for 13- to 15-year-old players; and up to eight training sessions or games per week for players 16 years or older. At the time of enrollment, each athlete had participated in a standardized training program for an average of $9.2 \pm 4.3$ years, starting at an age of 8 years or younger. The 37 participating athletes (72 hips) had an average age of $17.6+4.9$ years, (range, 9-25 years). One athlete was excluded as he had undergone hip arthroscopy for femoroacetabular impingement.

The age-matched control group consisted of 38 volunteers recruited from middle, high, and medical schools in Bern. Volunteers were recruited by written invitation and without reimbursement. In the control group we excluded individuals who currently participated in regular sports activities for more than 2 hours per week or had done so in the past. Volunteers were excluded if they reported hip pain or had a positive impingement test. One potential subject was excluded on this basis. The 38 individuals 
(76 hips) of the control group had an average age of $16.9+4.7$ years (range, $9-25$ years).

The study protocol included evaluation of both hips in each individual. A history regarding hip pain and sports activity was obtained via questionnaire (Appendix 1translated from German). The questionnaire focused on the individual's age at the start of basketball training, frequency of training per week, and occurrence and severity of pain in the hip, groin, greater trochanter, buttocks, or lower back within the previous 6 months. Physical examination included ROM of the hip with a special focus on internal rotation with the hip flexed to $90^{\circ}$ [26]. Additionally, the anterior impingement test was performed on each individual by one of the senior authors (TCM). This test was judged to be positive when sharp pain in the groin or anterolateral hip region was evoked when the hip was internally rotated in flexion and slight adduction.

To allow for more detailed analysis of the relationship between age and joint motion, both groups were further subdivided into four age groups: 9 to 12 years, 13 to 15 years, 16 to 21 years, and 22 to 25 years (Table 1). The control and athlete groups were similar in terms of age and body mass index (BMI). We found no variation in BMI of either group as a function of the age of the subjects.

MR arthrography currently is considered the best diagnostic tool for intraarticular hip disorders [7, 23, 44]. All participants underwent routine standardized MRI with radial sections of each hip without intraarticular contrast. In two athletes, only one hip could be examined by MRI owing to technical problems, reducing the number to 72 hips. MRI was performed on a 3.0 Tesla MR system (Siemens, Erlangen, Germany) using a large flexible surface coil. A proton-weighted radial sequence (TR, $2000 \mathrm{~ms}$; TE, $15 \mathrm{~ms}$; matrix, $512 \times 256$; FOV, $260 \times 260$; section thickness, $4 \mathrm{~mm}$; acquired sections, six) was used for accurate evaluation of the femoral head, femoral headneck junction, and acetabulum [44]. The radial planes were rotated clockwise in $30^{\circ}$-intervals around, and perpendicular to, the femoral neck axis (Fig. 1). In addition, a 3-D Trufisp sequence (TR, 13; TE, 5; matrix, $512 \times$ 512; FOV, 160; resolution, $0.55 \times 0.55 \times 0.55$; TA, 7:55 minutes) was obtained to assess the status of the capital growth plate.

Evaluation of the MRI slices included two components. First, the morphologic features of the head-neck junction were analyzed by measuring the alpha angle on predefined radial sections in the superior half of the femoral head, as this is the predominant location for cam-type deformities $[29,31]$. The alpha angle measures the segment of the head-neck junction not fitting a sphere and a value greater than $55^{\circ}$ generally is considered pathologic [29, 31]. In the original description by Nötzli et al. [29], the alpha angle was measured in one position in the horizontal plane. This position represents the most anterior head-neck junction ( 3 o'clock position in a left hip). However, the greatest alpha angles and/or least head-neck offset ratios typically seen in males with a cam-type impingement have been observed at the superoanterior head-neck portion [15, 31, 37]. This location, in a clockwise system, approximates the 1 o'clock position [15, 17, 37]. Thus we found it more appropriate to analyze the alpha angles throughout the entire cranial hemisphere of the femoral head in a clockwise system from the 9 o'clock (posterior) to the 3 o'clock positions (anterior) (Fig. 1). This allowed analysis of the (patho)morphologic features more accurately throughout spatial distribution. The analysis was simplified by converting right-sided images into left-sided joints. Second, the status of the capital growth plate (open versus closed) was evaluated. The assumption is that the deformity has a developmental character. Thus, growth abnormality is expected to increase as long as the growth plate is still open and it should reach a maximum after physeal closure. The capital physis was considered closed when it was represented only by a complete black line similar to cortical or sclerotic bone on proton-weighted sequences and a lack of increased signal on the T2 or Trufisp sequences. A bright signal on the latter

Table 1. Distribution of potential confounding factors*

\begin{tabular}{|c|c|c|c|c|c|}
\hline Age (years) & Individuals & Mean age (years) & $\mathrm{p}$ Value & BMI & $\mathrm{p}$ Value \\
\hline \multirow[t]{2}{*}{$9-12$} & Basketball players & $10.5(+1.0)$ & 0.750 & $18.2(+2.8)$ & 0.562 \\
\hline & Control group & $10.7(+1.1)$ & & $17.5(+2.8)$ & \\
\hline \multirow[t]{2}{*}{$13-15$} & Basketball players & $14.1(+0.6)$ & 0.876 & $20.6(+3.2)$ & 0.894 \\
\hline & Control group & $14.1(+0.7)$ & & $20.7(+3.1)$ & \\
\hline \multirow[t]{2}{*}{ 16-21 } & Basketball players & $18.3(+1.8)$ & 0.954 & $22.8(+2.4)$ & 0.087 \\
\hline & Control group & $18.3(+2.3)$ & & $21.4(+3.2)$ & \\
\hline \multirow[t]{2}{*}{$22-26$} & Basketball players & $23.9(+1.0)$ & 0.127 & $24.9(+1.6)$ & 0.135 \\
\hline & Control group & $23.6(+1.0)$ & & $24.5(+1.8)$ & \\
\hline
\end{tabular}

* Age and body mass index (BMI); Student's t-test was used for comparsion between the two different study groups (basketball players and control group); $\mathrm{p}<0.05$ indicates statistical differences. 


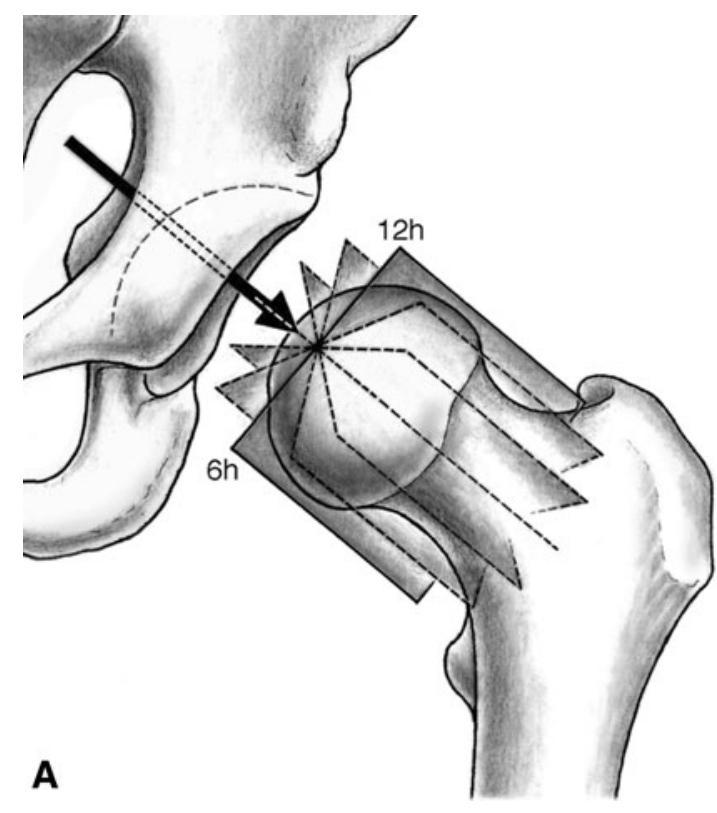

Fig. 1A-B (A) The radial MRI planes, which are perpendicular to the femoral head-neck axis, are defined on a sagittal oblique localizer. (B) The radial cuts rotate clockwise in $30^{\circ}$-intervals around the

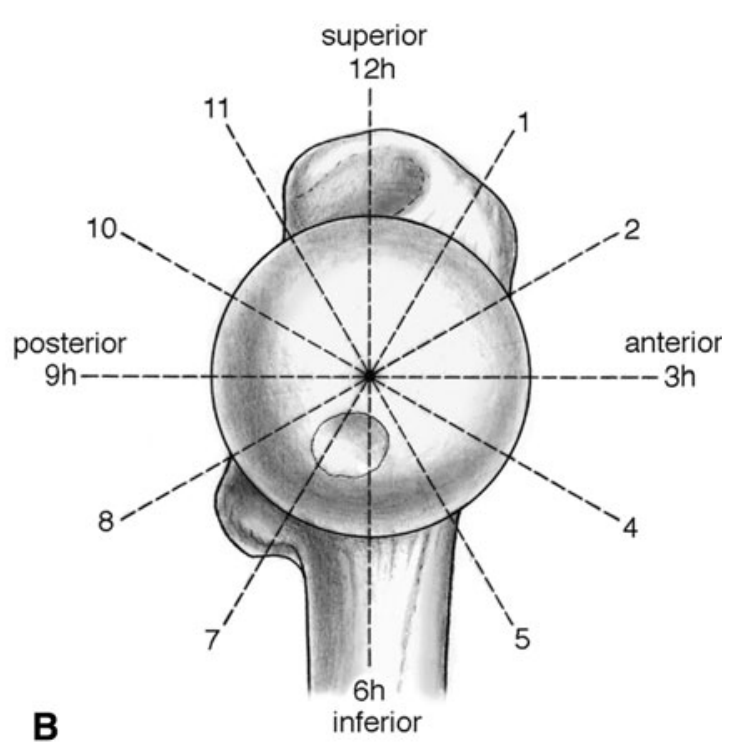

femoral head-neck axis. The alpha angle measurements were performed throughout the cranial hemisphere from 9 o'clock to 3 o'clock.
Fig. 2A-D (A) An MRI scan of the femoral head of a 12-yearold boy is shown. The bright enhancement line (white arrow) indicates an open growth plate. (B) The open physis is represented by a broad and dark line on the proton density-weighted sequence. The round circle indicates the spherical contour of the head. The alpha angle is $30^{\circ}$. (C) A MRI scan of the femoral head of a 14-year-old boy is shown with no enhancement of the growth plate indicating a closed physis. (D) The closed physis in the 14-year-old boy is represented by a thin, irregular grey line. The round circle indicates the spherical contour of the head. The alpha angle is $40^{\circ}$.
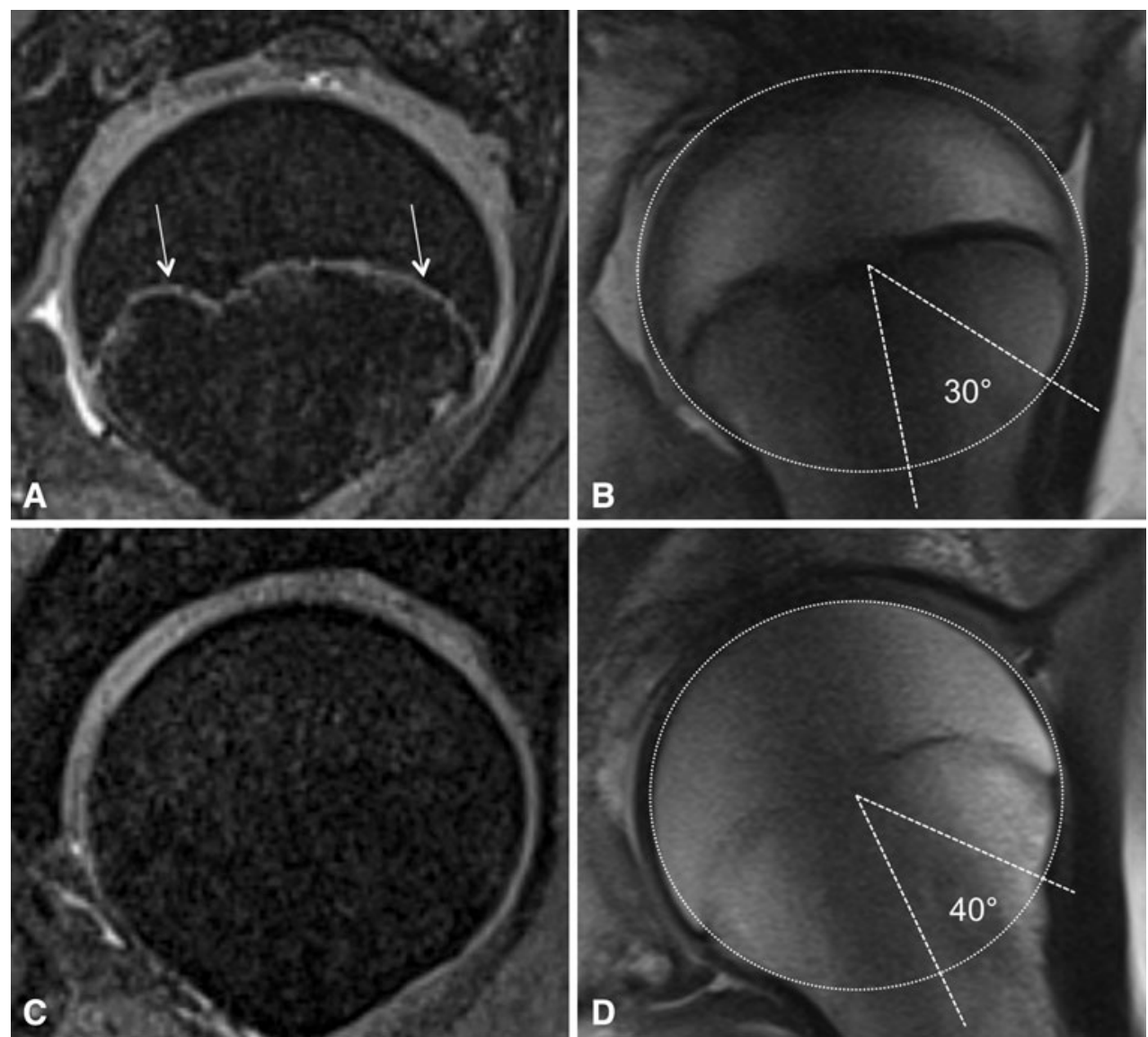

two sequences indicates a higher water content and/or cartilage, which typically are seen in open physes [10, 11, 36] (Fig. 2). The alpha angles at the seven defined positions were compared between the two groups. Subsequently the two groups were subdivided into two subgroups according to whether the physis was open or closed. 
Two observers (FF, TCM) performed the alpha angle measurements on the MRI scans independently. One observer (TCM) repeated the measurements 4 weeks later while being blinded to the previous results. Intraobserver and interobserver variability of the measured alpha angle were assessed. Mean values for both observers were used for further analysis.

We determined differences in alpha angles between the athletes and the control group using the parametric Student's t-test. Distribution of alpha angles within the groups to use the parametric test were assessed with the Kolmogorov-Smirnov test. Variations in internal rotation of the hip between the different age groups for athletes and control group were analyzed using ANOVA. When we detected statistical significance, we tested differences between specific groups using the Duncan post hoc analysis test. The correlation between age and internal rotation was determined using the Pearson product moment correlation coefficient after a normal distribution was confirmed using the Kolmogorov-Smirnov test. All analyses were performed using the Statistical Package for the Social Sciences version 16.0 (SPSS Inc, Chicago, IL, USA).

\section{Results}

The athletes had greater $(\mathrm{p}<0.001)$ mean alpha angles throughout the anterosuperior head-neck quadrant (Table 2) with the highest mean alpha angle $\left(60.5^{\circ}\right)$ at the 1 o'clock position.
After physeal closure the mean alpha angles in the anterosuperior quadrant were greater $(p<0.001)$ in the athletes when compared with the average values before closure (Table 3). The greatest mean alpha angle was $64.3^{\circ} \pm 7.6^{\circ}$ at the $1 \mathrm{o}^{\prime}$ clock position in hips with a closed physis. The control group showed no difference in mean alpha angles before and after growth plate closure (Fig. 3). After physeal closure, a higher percentage $(\mathrm{p}=0.001)$ of the athletes had an alpha angle of $55^{\circ}$ or greater at least at one measurement site compared with the control group: $89 \%$ (41 of 46 hips) versus 9\% (four of $44 \mathrm{hips}$ ), respectively (Fig. 4). When stratified into four age groups, we found an inverse correlation $(\mathrm{r}=-0.553 ; \mathrm{p}=0.01)$ between the alpha angle and internal rotation for the athletes after physeal closure at the $1^{\circ} \mathrm{o}$ 'clock position, which represents the typical position for the most pronounced cam-type deformity. There was no such correlation for athletes with an open physis or control subjects.

Reported hip pain or elicited pain by the anterior impingement test was far more frequent in athletes than in control subjects. Seven of 37 athletes (19\%) reported they had experienced pain around the hip within the 6 months preceding the date of evaluation, especially during or after physical activity. In four of these seven athletes, the hip pain was bilateral. In the total sample of 72 hips in the athlete group, 11 hips (15\%) had a reported painful episode during the previous 6 months. In all of these 11 hips, pain also could be elicited by the anterior impingement test. In an additional 29 of the remaining 61 hips (48\%), the impingement test evoked sharp groin pain despite the

Table 2. Comparison of alpha angle distribution ${ }^{\dagger}$

\begin{tabular}{|c|c|c|c|c|c|c|c|c|}
\hline \multirow[t]{2}{*}{ Group } & \multirow{2}{*}{$\begin{array}{l}\text { Number } \\
\text { of hips }\end{array}$} & \multicolumn{7}{|c|}{ Alpha angle (degrees) } \\
\hline & & 9 o'clock & 10 o'clock & 11 o'clock & 12 o'clock & 1 o'clock & 2 o'clock & 3 o'clock \\
\hline Athletes & $\mathrm{N}=72$ & $37.6( \pm 6.2)$ & $36.2( \pm 6.2)$ & $40.8( \pm 5.2)$ & $57.8( \pm 10.6)$ & $60.5( \pm 9.1)$ & $53.8( \pm 9.2)$ & $50.1( \pm 6.8)$ \\
\hline Control subjects & $\mathrm{N}=76$ & $39.1( \pm 4.4)$ & $40.1( \pm 4.9)$ & $41.0( \pm 4.3)$ & $49.5( \pm 5.8)$ & $47.4( \pm 4.3)$ & $42.1( \pm 4.5)$ & $37.6( \pm 4.8)$ \\
\hline p Values & & 0.130 & $* 0.024$ & 0.228 & $* 0.001$ & $* 0.001$ & $* 0.001$ & $* 0.001$ \\
\hline
\end{tabular}

${ }^{\dagger}$ Mean values + standard deviation between athletes and control subjects; * statistical differences in alpha angle distribution $(\mathrm{p}<0.01)$.

Table 3. Comparison of alpha angle distribution ${ }^{\dagger}$

\begin{tabular}{llllllllll}
\hline Group & Physis & $\begin{array}{l}\text { Number } \\
\text { of hips }\end{array}$ & 9 o'clock & 10 o'clock & 11 o'clock & 12 o'clock & 1 o'clock & 2 o'clock & 3 o'clock \\
\hline Athlete & Open & $\mathrm{N}=26$ & $39.6( \pm 6.4)$ & $36.0( \pm 6.5)$ & $42.5( \pm 4.9)$ & $52.2( \pm 7.4)$ & $53.7( \pm 7.4)$ & $49.8( \pm 5.8)$ & $48.6( \pm 5.6)$ \\
& Closed & $\mathrm{N}=32$ & $36.5( \pm 5.9)$ & $36.3( \pm 6.1)$ & $39.8( \pm 5.2)$ & $60.9^{*}( \pm 10.9)$ & $64.3^{*}( \pm \pm 7.6)$ & $56.1 *(+10.0)$ & $50.9( \pm 7.3)$ \\
Control & Open & $\mathrm{N}=46$ & $40.5( \pm 4.9)$ & $41.14( \pm 4.4)$ & $41.9( \pm 3.8)$ & $49.3( \pm 6.2)$ & $47.5( \pm 5.7)$ & $42.9( \pm 5.2)$ & $39.2( \pm 5.4)$ \\
subject & Closed & $\mathrm{N}=44$ & $37.9( \pm 4.7)$ & $39.1( \pm 6.4)$ & $40.4( \pm 4.5)$ & $49.6( \pm 5.6)$ & $47.4( \pm 6.8)$ & $41.7( \pm 7.4)$ & $36.5( \pm 5.5)$
\end{tabular}

$\uparrow$ Mean values + standard deviation between athletes and control subjects up for closed; $*$ significant differences $(\mathrm{p}<0.01)$ from open to closed epiphysis in each group. 


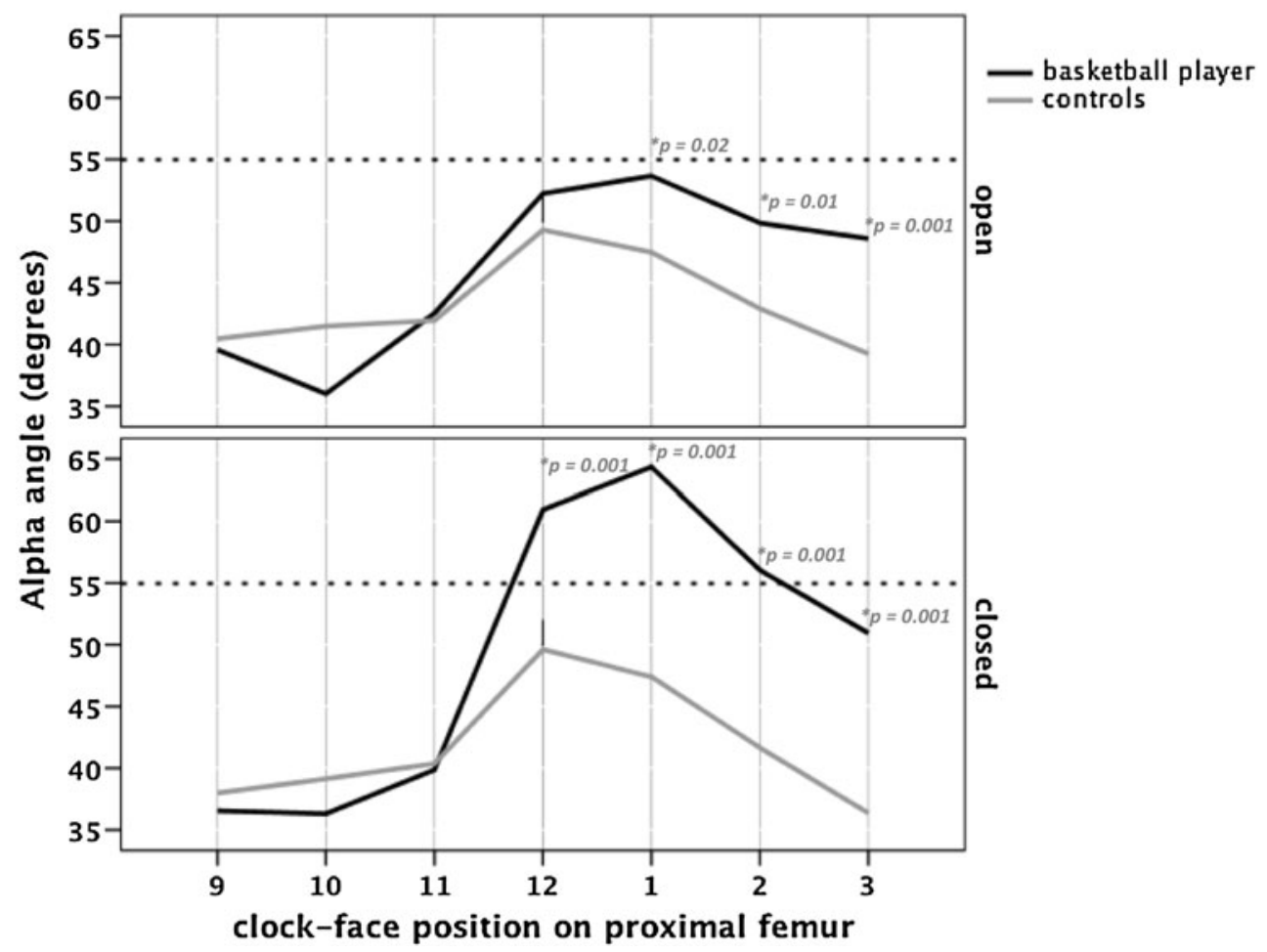

Fig. 3 The average alpha angles at the different positions of the cranial hemisphere of the femoral head in the athlete and control groups are shown. The two groups were further separated into two subgroups according to an open $(\mathrm{n}=27$ hips in the athlete group, $\mathrm{n}=32$ hips in the control group) or closed capital growth plate ( $n=45$ hips in the athlete group, $n=44$ hips in the control group).
Fig. 4A-B The alpha angles at the 2 o'clock position in (A) a 16-year-old athlete with severe cam-type morphologic features (white arrow) and (B) a 17-year old control subject are shown. The white circle indicates the spherical outline of the head on each figure.
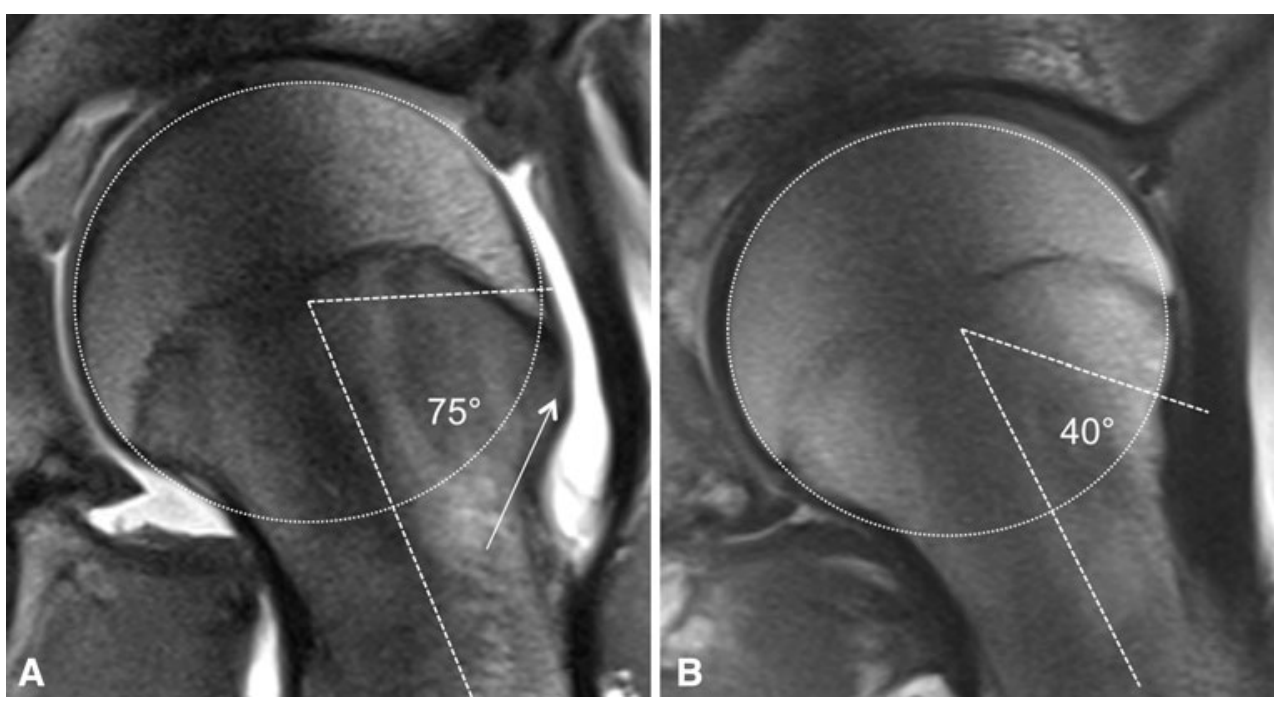

absence of any history of hip pain in the 6 months before evaluation. Of the 39 recruited control subjects, one had a positive impingement test on one side despite an absent history for hip pain. Thus, the prevalence for a positive impingement test in the control group was one of 78 hips (1.3\%). According to the inclusion criteria, this individual was excluded from the study and further MRI studies.
Internal rotation of the hip in flexion was decreased $(\mathrm{p}<0.001)$ in the athletes compared with the control subjects: $\quad 18.9^{\circ} \pm 11.0^{\circ} \quad$ (range, $0^{\circ}-45^{\circ}$ ) versus $30.1^{\circ} \pm 6.9^{\circ}$ (range, $15^{\circ}-45^{\circ}$ ). When stratified into four age groups, internal rotation of the athletes decreased by an average of $22.5^{\circ}$ from the youngest (9-12 years) to the oldest (22-26 years) groups, compared with only $10.2^{\circ}$ in individuals of the control group (Table 4; Fig. 5). 
Table 4. Distribution of internal rotation in different age categories

\begin{tabular}{|c|c|c|c|c|c|}
\hline \multirow{2}{*}{$\begin{array}{l}\text { Age of subject } \\
\text { (years) }\end{array}$} & \multicolumn{2}{|l|}{ Athletes } & \multicolumn{2}{|l|}{ Control subjects } & \multirow[b]{2}{*}{ p Values } \\
\hline & Number of hips & Internal rotation Degrees/( $\pm \mathrm{SD})$ & Number of hips & $\begin{array}{l}\text { Internal rotation } \\
\text { Degrees/ }( \pm \mathrm{SD})\end{array}$ & \\
\hline $9-12$ & $\mathrm{~N}=12$ & $34.2( \pm 11)$ & $\mathrm{N}=14$ & $37.1( \pm 5.4)$ & 0.257 \\
\hline $13-15$ & $\mathrm{~N}=16$ & $23.4( \pm 5.4)$ & $\mathrm{N}=22$ & $31.8( \pm 4.5)$ & $* 0.001$ \\
\hline $16-21$ & $\mathrm{~N}=25$ & $13.6( \pm 7.6)$ & $\mathrm{N}=21$ & $25.7( \pm 7.6)$ & $* 0.001$ \\
\hline $22-26$ & $\mathrm{~N}=19$ & $12.4( \pm 8.4)$ & $\mathrm{N}=19$ & $27.8( \pm 4.1)$ & $* 0.001$ \\
\hline
\end{tabular}

* Statistical difference $(\mathrm{p}<0.01)$ between control subject and athletes in one age group.

Fig. 5 The distribution of internal rotation in the different age subgroups in the athlete and control groups is shown.

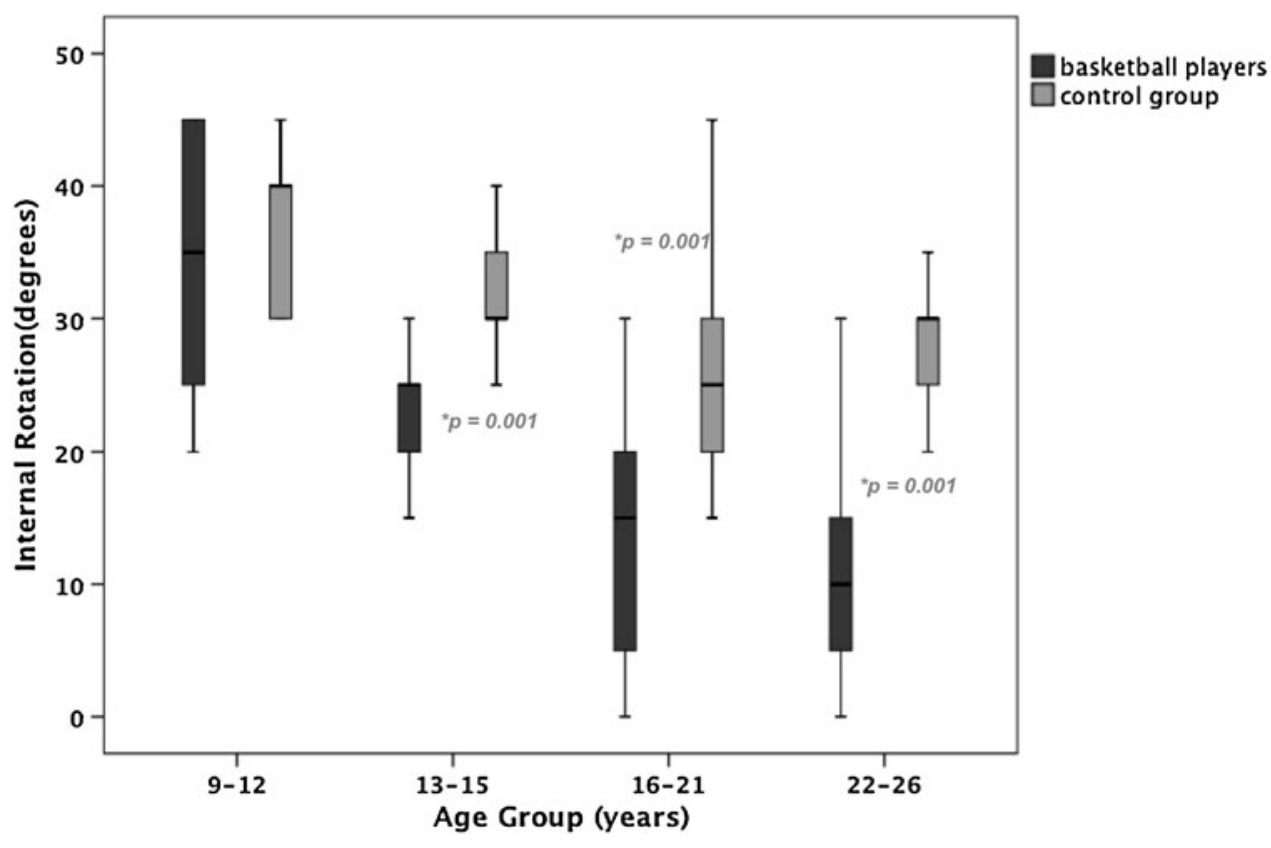

\section{Discussion}

The prevalence of hip osteoarthritis is higher in athletes than in those who do not participate in regular sports, and depends on the intensity of athletic activities and the physical loading of the hip [24, 25, 42]. Male athletes, especially those engaged in soccer, handball, and competitive track and field activities (running and jumping sports), reportedly have an earlier onset and increased risk of osteoarthritis of the hip [9, 21, 24, 25, 28, 42, 43]. One study [28] suggests there is an increased prevalence of hip pain in athletes, including elite athletes, with cam-type pathomorphologic features of the femur. To confirm and supplement these findings, we therefore asked whether: (1) the prevalence of a cam-type deformity of the proximal femur is greater in male athletes compared with nonathletes; (2) the cam-type deformity is less pronounced in childhood but increases with participation in vigorous physical activities during hip development and physeal closure; and (3) hip pain and decreased internal rotation of the hip are more frequent in male athletes than in healthy control subjects.

Our study has some limitations. First, owing to the selection criteria of the control group, the alpha angles of the athletes were compared with those of pain-free functioning hips (no cross-sectional analysis). However, we suspect that in children and adolescents with an average age of 16.9 years, it is justified to use a pain-free hip as a standard for comparison. Second, we did not obtain conventional radiographs of the hip because of ethical concerns regarding radiation exposure of young individuals. However, we presume we could rule out disorders like hip dysplasia or a slipped capital epiphysis with the MRI sections. Third, although our observations confirm morphologic differences between the two groups, they do not tell us what triggers the deformity in athletes. Although determining the stimulus was beyond the scope of this study, the high activity levels in the experimental group 
suggest something about the cumulative loading triggers some sort of bony adaptation. Fourth, we did not assess labral or cartilage lesions as noncontrast MR studies of the hip are less accurate in showing these lesions than contrastenhanced MRI scans, which can be regarded as the current diagnostic standard [31]. However, lack of contrast did not affect measurements of alpha angles.

We observed that the cam-type deformity of the proximal femur is more frequent in athletes than for agematched individuals not participating in high-level sports activities. We believe this to be the case as we observed elevated alpha angles throughout the anterosuperior headneck quadrant in the athletes compared with the control group. The greatest mean alpha angle in the athletes was measured at the $1^{\circ}$ clock position. This observation is consistent with findings in the literature where the anterosuperior head-neck quadrant and especially the anterosuperior area $\left(1^{\circ}\right.$ to $2^{\circ}$ position) has been described as the predominant site of the cam-type deformity $[15,31$, 37].

In the athletes the alpha angles increased during or after closure of the growth plate to abnormal high values. Although elevated compared with the control group, the alpha angles were still within normal limits in athletes with an open physis after undergoing training for an average of $5.5 \pm 2.8$ years. Currently, in healthy study groups, an alpha angle as much as $50^{\circ}$ to $55^{\circ}$ is considered normal [8, 15, 29, 34] (Table 5). After physeal closure, the prevalence of an alpha angle of $55^{\circ}$ or greater at any measurement position in the control subjects was four (9\%) of 44 hips. This finding concurs with the prevalence reported by numerous authors [8, 15, 29, 34] (Table 5). In athletes, we found an alpha angle of $55^{\circ}$ or greater in 41 (89\%) of 46 hips in the anterosuperior head quadrant, which represents a nearly 10 -fold increase in the athlete hips.

The pathomechanism for the increase in alpha angles in the athletes during the growth period is unknown. Vigorous exercise may trigger the deformity, as high skeletal stresses have been associated with a pathologic skeletal growth pattern and morphologic alterations in gymnasts and baseball players $[5,6]$. We speculate the cumulative effect of high stresses and perhaps more or less subtle differences in the direction of loading on the proximal femur during growth may modulate growth toward an abnormal shape. This notion was suggested by Murray and Duncan [28], who observed the greatest prevalence $(24 \%)$ of femoral head tilt deformities in adolescents who started a compulsory sports regimen during boarding school before the age of 14 years [28].

Seven of the 37 athletes (19\%) reported at least one episode of hip pain during the last 6 months. In the affected hips pain also could be elicited by the impingement examination. In a previous cohort study of 1097 young Swiss male army recruits (average age, 19.9 years), individuals were screened with a similar questionnaire and underwent an impingement examination [35]. Only 17 (1.5\%) of the 1097 subjects studied had painful hips and/or had undergone previous hip surgeries. The percentage of these individuals who participated in sports activities at a competitive level is unknown, but presumably is low. Thus, the basketball players reported more than a 12-fold increase in the rate of hip pain.

We also found an association between athletic activity and a more pronounced decrease in internal rotation of the hip compared with the study group. In the youngest age group studied (9-12 years), internal rotation was similar for the athletes and control subjects $\left(34.2^{\circ} \pm 11.0^{\circ}\right.$ versus $\left.37.1^{\circ} \pm 5.4^{\circ} ; \mathrm{p}=0.257\right)$. However, from age 13 to 15 years on, there was a larger decrease in internal rotation in the athletes compared with the control subjects, which became more pronounced up to 25 years of age. A physiologic loss of internal rotation attributable to decreasing femoral neck anteversion during growth has been described $[41,45]$. However, the substantially decreased internal

Table 5. Alpha angle measurements in volunteers

\begin{tabular}{|c|c|c|c|c|c|}
\hline Study & $\begin{array}{l}\text { Number of } \\
\text { volunteers }\end{array}$ & Alpha angle measurement & Mean alpha angle & $\begin{array}{l}\text { Incidence of head-neck } \\
\text { offset changes }\end{array}$ & $\begin{array}{l}\text { Cut off value of head-neck } \\
\text { offset changes }\end{array}$ \\
\hline $\begin{array}{l}\text { Nötzli et al. } \\
\text { [29] }\end{array}$ & $\mathrm{N}=40$ & $\begin{array}{l}\text { MRI (axial plane through } \\
\text { femur) }\end{array}$ & $\begin{array}{l}42.0^{\circ} \pm 2.2^{\circ} \\
\left(33^{\circ}-48^{\circ}\right)\end{array}$ & Not assessed & Not assessed \\
\hline $\begin{array}{l}\text { Hack et al. } \\
\text { [15] }\end{array}$ & $\mathrm{N}=200$ & $\begin{array}{l}\text { MRI (anterior and } \\
\text { anterosuperior position) }\end{array}$ & $\begin{array}{l}40.9^{\circ} \pm 7.0^{\circ} \\
\text { anterior } \\
50.2^{\circ} \pm 8.2^{\circ} \\
\text { anterosuperior }\end{array}$ & $\begin{array}{l}14 \% \text { with at least one hip } \\
\text { with changes }\end{array}$ & Alpha angle $>50.5^{\circ}$ \\
\hline $\begin{array}{l}\text { Pollard et al. } \\
\text { [34] }\end{array}$ & $\mathrm{N}=83$ & Lateral radiograph & Not assessed & $\begin{array}{l}14.5 \% \text { with at least one hip } \\
\text { with changes }\end{array}$ & Alpha angle $>55^{\circ}$ \\
\hline $\begin{array}{l}\text { Doherty } \\
\text { et al. [8] }\end{array}$ & $\mathrm{N}=1109$ & AP radiograph & Not assessed & $\begin{array}{l}3.61 \% \text { with at least one hip } \\
\text { with changes }\end{array}$ & Head-neck ratio $<1.27$ \\
\hline
\end{tabular}


rotation in the athletes points toward a structural abnormality as an underlying cause. This is supported by the fact that the decrease in internal rotation in the athletes was associated with abnormal high alpha angles after the end of growth.

Our data suggest the cam-type deformity is in part a developmental deformity, and that its expression in young adulthood may be triggered by environmental factors such as high-level sports activity during childhood and around the time of closure of the capital growth plate. Given the role of the cam-type deformity in femoroacetabular impingement and early degenerative changes in the hip, we suggest changes in morphologic features of the femur resulting from vigorous sporting activity are a key component in the elevated incidence of hip osteoarthritis observed in athletes.

\section{Appendix}

UNIVERSITY BERN

INSELSPITAL

\section{PARTICIPANT QUESTIONNAIRE}

Name:

Date of birth:

Date of examination:

Examined hip:

right

left

Gender

female

male

Height / Body weight

cm 
UNIVERSITY BERN

INSELSPITAL

1. Please state additional (except basketball) regular sports activites within the last 12 months

Additional sports activity (1)

Additional sports activity (2)

Additional sports activity (3)

(1)

times per week

times per week

times per week

\section{Please state sports activities done before regulary (if stopped)}
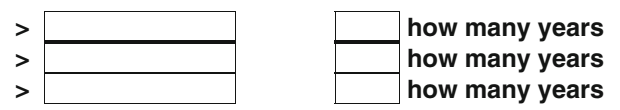

times per week times per week

times per week

3. At what age did you start basketball training?

years

4. I have pain in the hip within the last 6 months.

$\square$ yes

$\square$ no

5. Where exactly do you localize the pain?

Inguinal pain

Buttocks region

Greater trochanter

Lower back

Knee

\begin{tabular}{|c|c|}
\hline Left & Right \\
\hline Left & Right \\
\hline Lef & Right \\
\hline Lef & Right \\
\hline oft & Right \\
\hline
\end{tabular}




\section{UNIVERSITY BERN}

INSELSPITAL

\section{I have this pain within the last 6 month:}

- while lying in bed

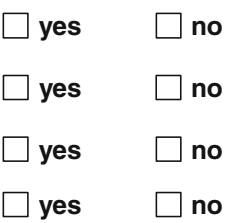

- while sitting (eg, TV watching, eating, etc)

- with daily activities of living (eg, walking)

$\square$ yes $\square$ no

- while stair climbing

$\square$ yes $\square$ no

- at sports training

no

If yes: are there specific training methods with increased pain?

$\square$ yes which?

\section{Have you observed limping while walking within the last 6 months?}

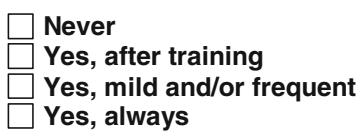

8. How you would grade range of motion in your hip

$$
\text { (1 = excellent, } 7 \text { = limited })
$$

$\begin{array}{lllllll}1 & 2 & 3 & 4 & 5 & 6 & 7\end{array}$

\author{
$>$ childhood (until 10 years) \\ > adolescent (until 16 years) \\ $>$ now
}

\section{References}

1. Beck M, Kalhor M, Leunig M, Ganz R. Hip morphology influences the pattern of damage to the acetabular cartilage. $J$ Bone Joint Surg Br. 2005;87:1012-1018.

2. Bharam S. Labral tears, extra-articular injuries, and hip arthroscopy in the athlete. Clin Sports Med. 2006;25:279-292.

3. Bigliani LU, Codd TP, Connor PM, Levine WN, Littlefield MA, Hershon SJ. Shoulder motion and laxity in the professional baseball player. Am J Sports. 1997;25:609-613.

4. Bizzini M, Nötzli HP, Maffiuletti NA. Femoroacetabular impingement in professional ice hockey players: a case series of 5 athletes after open surgial decompression of the hip. Am J Sports Med. 2007;35:1955-1959.

5. Caine D, DiFiori J, Maffulli N. Physeal injuries in children's and youth sports: reasons for concern? Br J Sports Med. 2006; 40:749-760.

6. Carson WG, Gasser SI. Little leaguers' shoulder: a report of 23 cases. Am J Sports Med. 1998;26:575-580.
7. Czerny C, Hofmann S, Neuhold A, Tschauner C, Engel A, Recht MP, Kramer J. Lesions of the acetabular labrum: accuracy of MI imaging an MR arthrography in detection and staging. Musculoskelet Radiol. 1996;200:225-230.

8. Doherty M, Courtney P, Doherty S, Jenkins W, Maciewicz RA, Muir K, Zhang W. Nonspherical femoral head shape (pistol grip deformity), neck shaft angle, and risk of hip osteoarthritis. Arthritis Rheum. 2008;58:3172-3182.

9. Drawer S, Fuller CW. Propensity for osteoarthritis and lower limb joint pain in retired professional soccer players. Br J Sports Med. 2001;35:402-408.

10. Dvorak J, George J, Junge A, Hodler J. Age determination by magnetic resonance imaging of the wrist in adolescent male football players. Br J Sports Med. 2007;41:45-52.

11. Ecklund K, Jaramillo D. Patterns of premature physeal arrest: MR imaging of 111 children. AJR Am J Roentgenol. 2002;178:967-972.

12. Ganz R, Leunig M, Leunig-Ganz K, Harris WH. The etiology of osteoarthritis of the hip: an integrated mechanical concept. Clin Orthop Relat Res. 2008;466:264-272. 
13. Ganz R, Parvizi J, Beck M, Leunig M, Notzli H, Siebenrock KA. Femoroacetabular impingement: a cause for osteoarthritis of the hip. Clin Orthop Relat Res. 2003;417:112-120.

14. Goodman DA, Feighan JE, Smith AD, Latimer B, Buly RL, Cooperman DR. Subclinical slipped capital femoral epiphysis; relationship to osteoarthrosis of the hip. J Bone Joint Surg Br. 1997;83:1119-1124.

15. Hack K, Di Primio G, Rakhra K. Beaulé PE: Prevalence of camtype femoroacetabular impingement morphology in asymptomatic volunteers. J Bone Joint Surg Am. 2010;92:2436-2444.

16. Harris WH. Etiology of osteoarthritis of the hip. Clin Orthop Relat Res. 1986;213:20-33.

17. Ito K, Minka-II MA, Leunig M, Werlen S, Ganz R. Femoroacetabular impingement and the cam-effect. J Bone Joint Surg Br. 2001;83:171-176.

18. Kassarjian A, Brisson M, Palmer WE. Femoroacetabular impingement. Eur J Radiol. 2007;63:29-35.

19. Kassarjian A, Yoon LS, Belzile E, Connolly SA, Millis MB, Palmer WE. Triad of MR arthrographic findings in patients with cam-type femoroacetabular impingement. Radiology. 2005;236: 588-592.

20. Keogh MJ, Batt ME. A review of femoroacetabular impingement in athletes. Sports Med. 2008;38:863-878.

21. Kettunen JA, Kujala UM, Raty H, Videman T, Sarna S, Impivaara $\mathrm{O}$, Koskinen S. Factors associated with hip joint rotation in former elite athletes. Br J Sports Med. 2000;34:44-48.

22. Lavigne M, Parvizi J, Beck M, Siebenrock KA, Ganz R, Leunig M. Anterior femoroacetabular impingement: Part I. Techniques of joint preserving surgery. Clin Orthop Relat Res. 2004;418:6166.

23. Leunig M, Werlen S, Ungersböck A, Ito K, Ganz R. Evaluation of the acetabular labrum by MR arthrography. J Bone Joint Surg Br. 1997;79:230-234.

24. L'Hermette M, Polle G, Tourny-Chollet C, Dujardin F. Hip passive range of motion and frequency of radiographic hip osteoarthritis in former elite handball players. Br J Sports Med. 2006;40:45-49.

25. Lindberg H, Roos, H, Gärdesell P. Prevalence of coxarthrosis in former soccer players. Acta Orthop Scand. 1993;64:165-167.

26. MacDonald SJ, Garbuz D, Ganz R. Clinical evaluation of the symptomatic young adult hip. Semin Arthroplasty. 1979;8:3-9.

27. Murray RO. The aetiology of primary osteoarthritis of the hip. $\mathrm{Br}$ J Radiol. 1965;38:810-824.

28. Murray RO, Duncan C. Athletic acitivity in adolescence as an etiological factor in degenerative hip disease. J Bone Joint Surg Am. 1971;53:406-419.

29. Notzli HP, Wyss TF, Stoecklin CH, Schmid MR, Treiber K, Hodler J. The contour of the femoral head-neck junction as a predictor for the risk of anterior impingement. J Bone Joint Surg Br. 2002;84:556-560.

30. Ochoa LM, Dawson L, Patzkowski JC, Hsu JR. Radiographic prevalence of femoroacetabular impingement in a young population with hip complaints is high. Clin Orthop Relat Res. 2010; 468:2710-2714.
31. Pfirrmann CW, Mengiardi B, Dora C, Kalberer F, Zanetti M, Hodler J. Cam and pincer femoroacetabular impingement: characteristic MR arthrographic findings in 50 patients. Radiology. 2006;240:778-785.

32. Philippon M, Schenker M, Briggs K, Kuppersmith D. Femoroacetabular impingement in 45 professional athletes: associated pathologies and return to sport following arthroscopic decompression. Knee Surg Sports Traumatol Arthrosc. 2007;15:908914.

33. Pollard TC, Villar RN, Norton MR, Fern ED, Williams MR, Murray DW, Carr AJ. Genetic influences in the aetiology of femoroacetabular impingement: a sibling study. J Bone Joint Surg Br. 2010;92:209-216.

34. Pollard TC, Villar RN, Norton MR, Fern ED, Williams MR, Simpson DJ, Murray DW, Carr AJ. Femoro-acetabular impingement and classification of the cam deformity: the reference interval in normal hips. Acta Orthop 2010;81:134-141.

35. Reichenbach S, Jüni $P$, Werlen $S$, Nüesch E, Pfirrmann CW, Trelle S, Odermatt A, Hofstetter W, Ganz R, Leunig M. Prevalence of cam-type deformity on hip magnetic resonance imaging in young males: a cross-sectional study. Arthritis Care Res (Hoboken). 2010;62:1319-1327.

36. Sasaki T, Ishibashi Y, Okamura Y, Toh S, Sasaki T. MRO evaluation of growth plate closure rate and pattern in the normal knee joint. J Knee Surg. 2003;15:72-76.

37. Siebenrock KA, Wahab KHA, Werlen S, Kalhor M, Leunig M, Ganz R: Abnormal extension of the femoral head epiphysis as a cause of cam impingement. Clin Orthop Relat Res. 2004;418:54 60.

38. Stulberg SD, Cordell LD, Harris WH, Ramsey OL, MacEwen GD. Unrecognized childhood disease: a major cause of idiopathic osteoarthritis of the hip. In: Amstutz HC, ed. The Hip: Proceedings of the Third Open Scientific Meeting of the Hip Society. Saint Louis, MO: CV Mosby; 1975:212-228.

39. Tannast M, Goricki D, Beck M, Murphy SB, Siebenrock KA. Hip damage occurs at the zone of femoroacetabular impingement. Clin Orthop Relat Res. 2008;466:273-280.

40. Tippett SR. Lower extremity strength and active range of motion in college baseball pitchers: a comparison between stance leg and kick leg. J Orthop Sports Phys Ther. 1986;8:10-14.

41. Tönnis D, Heinecke A. Acetabular and femoral anteversion: relationship with osteoarthritis of the hip. J Bone Joint Surg Am. 1999;81:1747-1770.

42. Vingard E, Alfredsson L, Goldie I, Hogstedt C. Sports and osteoarthrosis of the hip. Am J Sports Med. 1993;21:195-200.

43. Vingard E, Alfredsson L, Malchau H. Osteoarthritis of the hip in women and its relationship to physical load from sports activities. Am J Sports Med. 1998;26:78-82.

44. Werlen S, Leunig M, Ganz R. Magnetic resonance arthrography of the hip in femoroacetabular impingement: technique and findings. Oper Tech Orthop. 2005;15:191-203.

45. Zippel H. Untersuchungen zur Normalentwicklung der Formelemente am Hüftgelenk im Wachstumsalter. Beitr Orthop Traumat. 1971;18:225-270. 